\title{
Serotonin transporter genotype, morning cortisol and subsequent depression in adolescents
}

\author{
Ian M. Goodyer, Alison Bacon, Maria Ban, Tim Croudace and Joe Herbert
}

\section{Background}

The short (s) allele of the serotonin transporter gene promoter (5-HTTLPR) may be associated with exposure to social adversities and the subsequent onset of depressive illness in adulthood.

\section{Aims \\ To test in adolescents at high risk for depression whether the short ' $s$ ' allele is associated with levels of morning cortisol and the subsequent onset of a depressive episode. \\ Method \\ High-risk adolescents ( $n=403$ ) were genotyped for 5 -HTTLPR Salivary samples were obtained on four consecutive school days within $1 \mathrm{~h}$ of waking from $393(97.5 \%)$ individuals and 367 (91\%) underwent a mental state reassessment at 12 months.}

\section{Results}

Multilevel analysis revealed higher levels of salivary cortisol in short allele carriers $(S / s>s /|>| / \mid)$. A subsequent episode of depression was increased in those with higher cortisol and the ' $s$ ' allele, and independently by depressive symptoms at entry, in both genders.

\section{Conclusions}

The short allele of 5-HTTLPR may moderate the association between morning cortisol and the subsequent onset of a depressive episode.

\section{Declaration of interest}

None.
The liability for social adversities to increase the likelihood of unipolar depressions may be moderated by the short ('s') allele in the promoter region of the serotonin transporter gene (5HTTLPR), ${ }^{1,2-5}$ although at least two studies have been negative. ${ }^{6,7}$ A recent review of this gene-environment interaction $(\mathrm{G} \times \mathrm{E})$ concluded that some of these inconsistencies can be attributed to differences in the age and gender composition of the samples studied and to the methods used for assessing non-genetic variables. ${ }^{8}$ Meta-analysis of published research suggests that the interaction with social adversity remains equivocal. ${ }^{9}$ In addition there is a marked absence of physiological, cognitive and behavioural intermediate phenotypes that may contribute to the synergy among candidate genes and environments. For example, it has been suggested that personality-related cognitive vulnerabilities may be one of the intermediate mechanisms associated with variation in 5 -HTTLPR. ${ }^{10}$

Activity of the hypothalamic-pituitary-adrenal axis may also be influenced by the 's'5-HTTLPR genotype. Individuals homozygous for the short arm (s/s) of the 5-HTTLPR polymorphism have increased cortisol reactivity to psychosocial stress and this may increase susceptibility to depression. ${ }^{11,12}$ Prospective studies have shown that higher morning cortisol in well individuals is associated with increased likelihood of the subsequent onset of depression. ${ }^{13-15}$ Cortisol levels are also higher in the offspring of parents with depression, ${ }^{16,17}$ who are also more liable to depression. $^{16}$

These findings suggest that exploration of the relations between 5-HTTLPR and cortisol levels as contributing factors to the risk for depression might be fruitful. This is supported by considerable evidence from human and experimental studies for interactions between serotonin and cortisol (e.g. Andrews \& Matthews, Bhagwagar et al). ${ }^{18,19}$ In this paper we report findings from a prospective study of community-dwelling adolescents at high psychosocial risk for psychopathology. We tested the hypothesis that carriers of the serotonin transporter gene short ' $s$ ' allele would demonstrate: higher levels of morning cortisol; greater risk for depressive onsets; and moderation of the linkage between cortisol hypersecretion and subsequent depression.

\section{Method}

\section{Participants}

An adversity-enriched sample of 403 White adolescents 12 to 17 years of age was recruited over 36 months starting January 1999 and completed in March 2002. This strategy was utilised to increase the yield of participants who may develop a depressive episode; the sample is not intended to be epidemiologically representative of the Cambridgeshire school population since individuals were selected in terms of their risk score. Adolescents with a current or recent (3 months) mental illness were excluded from the study sample. As a condition of ethical approval those with a recent (previous 2 years) history of overt maltreatment or who were on the UK child protection register were also excluded.

All gave written informed consent for genotyping and hormone assay. All were currently mentally well and part of a prospective study of adolescents with existing psychosocial adversities. They were obtained from 11 secondary schools in the Cambridgeshire region of the UK. All 403 were genotyped for 5-HTTLPR, $393(97.5 \%)$ provided up to 4 days (range 2 to 4 , average 3.9) of salivary samples on consecutive school days within $1 \mathrm{~h}$ of waking, 367 (91\%, 200 males and 167 females; age: mean 14.2 years, s.d. $=1.1)$ completed a mental state reassessment 12 months after entry (completed March 2003). Although there was some attrition, there were no significant differences between the retained sample and those who were not followed up in terms of demographics (age, gender), risk status, morning cortisol levels, mean level of depressive symptoms or distribution of the 5-HTTLPR alleles.

\section{Psychosocial risk profile}

Adversity was defined as having a parent with a psychiatric history, or two or more other risks consisting of: two bereavements over 
the young person's lifetime, a negative emotional temperamental style, chronic ( $>6$ months) marital disharmony or parental separation, two recent undesirable life events or difficulties with family or friendships focused on the adolescent. Participants were given a risk score based on the number of adversities that could range from one through to six.

We have previously shown this patterning of two or more adversities to be associated with a five-fold increase in the risk for onset of an episode of major depression over 1 year with no dose-response relationship between the number of risks and subsequent illness. ${ }^{13}$ The adversity screen was confined to current and recent risk not lifetime or life-course factors.

\section{Measures}

\section{Psychopathology}

At entry the adolescents completed a semi-structured psychiatric interview (the K-SADS-PL) ${ }^{20}$ to ascertain current psychiatric diagnoses defined as an episode present now or within the past 3 months. Individuals were assessed for all disruptive behavioural and emotional disorders. Participants were reassessed at 12 months using the same measures and all episodes of DSM-IV ${ }^{21}$-defined major depression and probable major depression (four symptoms together with psychosocial impairment defined as a Children's Global Assessment Scale ${ }^{22}$ score of <60) over the follow-up period were recorded together with episodes of anxiety and behavioural disorders.

\section{Self-report depression symptoms}

All participants completed a 33-item self-report measure of current depressive symptoms (the Mood and Feelings Questionnaire $^{23}$ (MFQ)) at entry but only 388 (96\%) provided useable data. This questionnaire has established criterion-related validity as a screen for adolescents with unipolar depression. ${ }^{24}$ The internal consistency reliability in this sample was high (Cronbach's $\alpha=0.96)$.

\section{Cortisol assay}

Participants provided samples of saliva at $08.00 \mathrm{~h}$ and recorded their waking time on four consecutive schooldays within a week of the interview. Mean time between waking and morning cortisol collection was $50 \mathrm{~min}$. Cortisol was measured by ELISA (enzymelinked immunosorbent assay) on $20 \mu \mathrm{l}$ samples of saliva without extraction (antibody Cambio UK). Intra-assay variation was $5.7 \%$; inter-assay variation was $5.6 \%$. There is a correlation between plasma and salivary cortisol levels $(r=0.6)^{25}$ and between blood and cerebrospinal fluid (CSF) levels $(r=0.9) .{ }^{26}$ Results are reported in $\mathrm{ng} / \mathrm{ml}$.

\section{Genotyping}

Participants' DNA was harvested from separate saliva samples (Qiagen, Crawley, UK) and genotyped for 5-HTTLPR. The 5HTTLPR region was amplified using the primers 5'-ATGCCAGCACCTAACCCCTAATGT- ${ }^{\prime}$ and 5-GGACCGCAAGGTGGGCGGGA-3', which generates a $419 \mathrm{bp}$ and $375 \mathrm{bp}$ product for the ' $\mathrm{l}$ ' and ' $\mathrm{s}$ ' alleles respectively. The polymerase chain reaction mixture consisted of: $100 \mathrm{ng}$ genomic DNA, $10 \mathrm{mM}$ Tris- $\mathrm{HCl}(\mathrm{pH} 9.0)$, $1.5 \mathrm{mM} \mathrm{MgCl} 2,50 \mathrm{mM} \mathrm{KCl}, 0.1 \%$ Triton ${ }^{\mathbb{R}} \mathrm{X}-100,1.25 \mathrm{U}$ Taq DNA polymerase, $200 \mu \mathrm{M}$ dNTPs, $500 \mathrm{nM}$ each of forward and reverse primer and $100 \mu \mathrm{M}$ 7-Deaza-dGTP in a final reaction volume of $15 \mu \mathrm{l}$. The reaction conditions were $98^{\circ} \mathrm{C}$ for $7 \mathrm{~min}$, followed by 40 cycles of $96^{\circ} \mathrm{C}$ for $30 \mathrm{~s}, 61^{\circ} \mathrm{C}$ for $30 \mathrm{~s}$ and $72^{\circ} \mathrm{C}$ for $1 \mathrm{~min}$ with a final extension stage of $72^{\circ} \mathrm{C}$ for $10 \mathrm{~m}$. Polymerase chain reaction products were electrophoresed on a 3700 DNA analyser (Applied Biosystems) with semi-automated sizing and genotyping performed using GENESCAN v3.7 and GENOTYPER v3.7 software for Windows (Applied Biosystems).

Triallelic genotyping was performed using Taqman methodology on a 7900 Sequence Detection System (Applied Biosystems). A $181 \mathrm{bp}$ fragment was amplified using the primers 5'-GCAACCTCCCAGCAACTCCCTGTA-3' and 5'-GAGGTGCAGGGGGATGCTGGAA-3'. Each reaction contained two fluorogenic probes that are specific for the $\mathrm{L}_{\mathrm{A}}$ allele (5'-6FAM-CCCCCCTGCACCCCCAGCATCCC-3') and the $\mathrm{L}_{\mathrm{G}}$ allele (5'-VIC-CCCCTGCACCCCCGGCATCCCC- $\left.3^{\prime}\right)$. Polymerase chain reaction amplification of the DNA was completed using 50 ng DNA, 1x Taqman Universal Mastermix (Applied Biosystems), $500 \mathrm{nM}$ each of forward and reverse primer, $80 \mathrm{nM}$ FAM probe $\left(\mathrm{L}_{\mathrm{A}}\right.$ allele $)$ and $100 \mathrm{nM}$ VIC probe $\left(\mathrm{L}_{\mathrm{G}}\right.$ allele $)$ in a final reaction volume of $5 \mu \mathrm{l}$. Polymerase chain reaction amplification conditions were $96^{\circ} \mathrm{C}$ for $10 \mathrm{~m}$ followed by 40 cycles of $96^{\circ} \mathrm{C}$ for $15 \mathrm{~s}$ and $69^{\circ} \mathrm{C}$ for $1 \mathrm{~min}$. Following polymerase chain reaction amplification, an end-point reading of the fluorescence from each probe was taken, with the relative fluorescence of each probe used to genotype individuals. Genotyping was completed using the Sequence Detection System Software Version 2.1 (Applied Biosystems).

\section{Analysis}

Multilevel modelling of cortisol measurements. For each individual up to four cortisol measurements were available for analysis. Since these measures are not independent, mixed-effects linear regression procedures were used to perform multilevel analyses of the repeated cortisol data. Regression model estimation was through maximum likelihood procedures (STATA-10 for Windows $^{27}$, xt command). Within- and between-participant variance components were estimated for morning/waking cortisol measures after natural log transformation to improve normality. Main effects and interactions were tested and model selection used Akaike's information criterion (AIC). Entering and removing variables and interaction terms alters the overall goodness of fit of a model and changes the AIC. Given a dataset, several competing models may be ranked according to their AIC. The lowest AIC was chosen as the best fitting, taking into account model complexity. We determined the effects of daily sampling, gender, age and the 5-HTTLPR genotype with and without the triallelic single nucleotide polymorphism on hormone variation. Main effects and interactions were also tested using likelihood ratio (deviance) tests.

Ordinary logistic regression modelling of subsequent depression episode onsets. Subsequently we used standard logistic regression procedures to examine the association between morning waking cortisol levels and subsequent onset of a DSM-IV major depressive episode. Of particular interest was the moderating effect of genotype, i.e. whether any association between cortisol levels and DSM-IV major depressive disorder was influenced by 5 -HTTLPR. We included gender as a covariate, since cortisol levels in adolescents are usually higher in girls compared with boys ${ }^{28}$ and the short ' $s$ ' allele of the 5-HTTLPR gene may preferentially moderate the effects of social adversities on the liability for depression in females. ${ }^{3}$ We also included number of adversities and age at entry, as these varied between participants (see below).

\section{Results}

The psychosocial and clinical characteristics of the sample by genotype are shown in Table 1 . The risk ascertainment profile 


\begin{tabular}{|c|c|c|c|c|}
\hline Genotype & $\mathrm{I} / \mathrm{I}(n=153)$ & $\mathrm{I} / \mathrm{s}(n=161)$ & $\mathrm{s} / \mathrm{s}(n=89)$ & Statistics \\
\hline \multicolumn{5}{|l|}{ Adversities at entry, $n$ (\%) } \\
\hline 1 & $19(12)$ & $30(19)$ & $16(18)$ & \multirow[t]{4}{*}{$\chi^{2}=6.4$, d.f. $=6, P=0.38$} \\
\hline 2 & $68(44)$ & $81(50)$ & $44(49)$ & \\
\hline 3 & $49(32)$ & $36(22)$ & $22(24)$ & \\
\hline 4 or more & $17(11)$ & $14(9)$ & $7(8)$ & \\
\hline \multicolumn{5}{|l|}{ Gender, $n(\%)$} \\
\hline Females & $68(38)$ & $67(37)$ & $44(25)$ & \\
\hline Males & $85(38)$ & $94(42)$ & $45(20)$ & $\chi^{2}=1.42$, d.f. $=2, P=0.49$ \\
\hline Age, years: mean (s.d.) & $13.6(1.2)$ & $13.8(1.2)$ & $13.7(1.2)$ & $F=0.46$, d.f. $=2,385, P=0.30$ \\
\hline Any emotional disorder, $n$ (\%) & $10(7)$ & $13(8)$ & $3(3)$ & $\chi^{2}=1.77$, d.f. $=2, P=0.41$ \\
\hline Any behavioural disorder, $n$ (\%) & $9(6)$ & $3(2)$ & $5(6)$ & $\chi^{2}=3.92$, d.f. $=2, P=0.141$ \\
\hline Depressive symptoms, mean (s.d.) & $17.2(8.6)$ & $17.5(8.9)$ & $18.4(9.7)$ & $F=0.46$, d.f. $=2,385, P=0.63$ \\
\hline Subsequent depressive episode, $n$ (\%) & $12 / 135(9)$ & $13 / 152(9)$ & $7 / 80(9)$ & $\chi^{2}=0.01$, d.f. $=2, P=1.0$ \\
\hline
\end{tabular}

ranged from 1 through to 4 or more components (mean 2.3, maximum 6 , one risk only $16 \%$, two risks $47 \%$, three risks $27 \%$, four risks $9 \%$, five risks $<1 \%$, six risks $<1 \%$ ). There was no gender difference in this risk profile $\left(\chi^{2}=2\right.$, d.f. $\left.=5, P=0.241\right)$. The genotyping for the 'l' and ' $s$ ' alleles was successful in all 403 participants but the triallelic single nucleotide polymorphism was typed in only $352(88 \%)$. There was the expected distribution of this 5-HTTLPR polymorphism (1/1 153 (38\%); 1/s 161 (40\%); s/s $89(22 \%))$. ${ }^{1}$ Males $(n=224)$ and females $(n=179)$ did not differ $\left(\chi^{2}=1.42\right.$, d.f. $\left.=2, \quad P=0.49\right)$. Only $388(96 \%)$ of the adolescents completed the Mood and Feelings Questionnaire (MF-33). There were no associations between genotype and adversity (number or risks at study entry), mean level of depressive symptoms (MFQ-33 score), gender, age or proportions of those who became depressed. As expected, females at entry showed higher MFQ-33 scores than males (males 16.6 (s.d.=8.5) v. females 18.9 (s.d. =9.4); $F=6.77$, d.f. $=1,387, P=0.01$ ).

There were 26 anxiety episodes ( $6 \%$ of the sample, and consisting of 19 simple phobias, 5 generalised anxiety disorder and 2 separation anxiety disorder) and 17 (4\%) episodes of oppositional defiant disorder without an emotional disorder. There were no differences in diagnoses by genotype.

\section{Morning cortisol levels by 5-HTTLPR, gender and sample day}

There was no association between mean self-report depression scores and daily or overall mean cortisol levels (pair-wise correlations: females $(n=170)-0.12$ through to -0.14 , males ( $n=218) 0.04$ through to 0.13 , all $P>0.1$ ).
Results from the multilevel modelling of cortisol data are reported in Table 2. There was a significant main effect of genotype, gender (female $>$ male) and sample day (declining over the 4 days) on morning cortisol level. There was no main effect of adversity number or age at entry and no significant two-way interactions. In this adolescent population approximately $42 \%$ of the variance in cortisol was as a result of within-participant variation and $58 \%$ as a result of between-participant variation.

Between-participant multilevel regression revealed that only the main effects of genotype and gender remained significant (5-HTTLPR, $\beta=0.14$, s.e. $=0.03, \quad t=3.36, \quad P=0.001,95 \%$ CI $0.05-0.18$; female, $\beta=0.24$, s.e. $=0.05, t=4.75, P<0.0001,95 \%$ CI $0.14-0.35$; day, $\beta=-0.15$, s.e. $=0.25, t=-0.62, P=0.534,95 \%$ CI $-0.48-1.9)$ within-participant multilevel regression revealed that only the effects of sample day (declining levels over the 4 days) remained significant $(\beta=-0.03$, s.e. $=0.02, t=-2.62, P=0.009$, $95 \%$ CI -0.05 to -0.007$)$. The between-group findings for each gender are shown in Fig. 1.

A second analysis of the levels of 5-HTTLPR showed that both the heterozygote $(1 / \mathrm{s})$ and the homozygote $(\mathrm{s} / \mathrm{s})$ individuals of both genders had higher cortisol levels than the homozygote (1/ 1) participants (constant $\beta=0.88$, s.e. $=0.05, z=17.0, P<0.0001$, $95 \%$ CI 0.78 to $-0.98 ; 1 / \mathrm{s}, \beta=0.12$, s.e. $=0.06, z=2.1, P=0.037$, $95 \%$ CI $0.01-0.24 ; \mathrm{s} / \mathrm{s}, \beta=0.23$, s.e. $=0.07, z=3.26, P=0.001$, 95\% CI 0.09-0.37).

We also determined the contribution of the triallelic single nucleotide polymorphism in the ' $\mathrm{l}$ ' form of 5-HTTLPR. Lowexpressing allelic forms have recently been reported as being associated with adverse events and depression. ${ }^{29}$ Of the 263

\begin{tabular}{|c|c|c|c|c|c|}
\hline Variable & Coefficient & s.e. & $z$ & $P$ & $95 \% \mathrm{Cl}$ \\
\hline 5-HTTLPR & 0.11 & 0.03 & 3.36 & 0.001 & 0.05 to 0.18 \\
\hline Females & 0.24 & 0.05 & 4.66 & 0.0001 & 0.13 to 0.34 \\
\hline Day of sampling & -0.03 & 0.01 & -2.64 & 0.008 & -0.05 to 0.1 \\
\hline Adversity number at entry & 0.02 & 0.03 & 0.5 & 0.62 & -0.044 to 0.074 \\
\hline Constant & 0.63 & 0.1 & 5.99 & $<0.0001$ & 0.42 to 0.84 \\
\hline \multicolumn{6}{|l|}{ Variable components } \\
\hline Between participants & 0.44 & 0.02 & & & 0.40 to 0.48 \\
\hline Within participants & 0.51 & 0.01 & & & 0.49 to 0.53 \\
\hline Intraclass coefficient & 0.42 & 0.03 & & & 0.37 to 0.48 \\
\hline
\end{tabular}




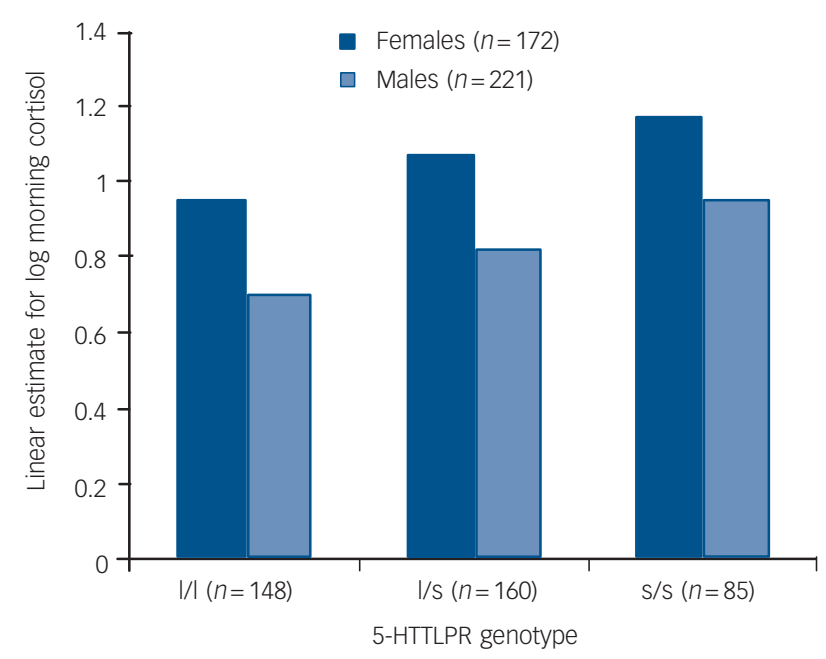

Fig. 1 Linear estimate of log morning cortisol by 5 -HTTLPR groups and gender.

individuals with one or more ' 1 ' alleles successfully typed for the single nucleotide polymorphism, $37(14 \%)$ carried one copy of the low-expressing $\mathrm{L}_{\mathrm{G}}$ allele; no $\mathrm{L}_{\mathrm{G}}$ homozygotes were found. We combined the $\mathrm{L}_{\mathrm{G}}$ with the ' $\mathrm{s} / \mathrm{s}$ ' group and recomputed the association with mean morning cortisol levels with the triallelic single nucleotide polymorphism as a dichotomous variable $\left(\mathrm{La} / \mathrm{La}(n=87)\right.$ v. $\left.\mathrm{L}_{\mathrm{A}} / \mathrm{L}_{\mathrm{G}+} \mathrm{L}_{\mathrm{A}} / \mathrm{s}+\mathrm{L}_{\mathrm{G}} / \mathrm{s}+\mathrm{s} / \mathrm{s}(n=265)\right)$, gender and sample day. With this reduced sample size, a modest significant association remained between higher morning waking cortisol and 5-HTTLPR low-expression genotype (low-expressing forms, $\beta=0.13$, s.e. $=0.067, z=1.94, P=0.05,95 \% \mathrm{CI}-0.001$ to -0.26 ).

\section{Predicting depressive episodes}

At follow-up, 32 of 367 adolescents reported an episode of clinical depression $(9 \%$ of the follow-up sample, of whom 5 had a comorbid anxiety disorder and 4 had comorbid oppositional defiant disorder). There were 19 onsets of anxiety episodes without depression (5\% of the follow-up sample, and consisting of 12 simple phobias, 5 generalised anxiety disorder and 2 separation anxiety disorder) and 14 (4\%) episodes of oppositional defiant disorder without an emotional disorder. Females were more likely to experience an episode of clinical depression over the follow-up period (males 11/200 (5\%) v. females 21/167 (13\%), $\left.\chi^{2}=5.72, \quad P=0.017\right)$. Those who became depressed reported higher levels of depressive symptoms at entry than those who did not ( $n=330$, including those with an episode of anxiety or of oppositional defiant disorder) (mean MFQ-33 depression scores: depressed 24.3 (s.d. $=8.7) \quad$ v. not depressed 16.9 (s.d.=8.7), $F=21.19$, d.f. $=1,360, P<0.001)$. Mean morning cortisol levels were also significantly higher in those who subsequently became depressed compared with those who did not (log mean cortisol: not depressed $0.98($ s.d. $=0.5) v$. depressed $1.2(0.4), F=6.41$, d.f. $=1,364, P=0.012$ ). Because the numbers of those reporting subsequent onset of depression were low, we combined $1 / \mathrm{s}$ and $\mathrm{s} / \mathrm{s}$ cases into one ' $\mathrm{s}$ ' group. Using ordinary logistic regression we determined whether the onset of an episode of clinical depression was associated with 5-HTTLPR genotype (1/l v. $1 / \mathrm{s}+\mathrm{s} / \mathrm{s}$ ) and morning cortisol together with depressive symptoms, gender, age, adversity number at entry and sample day. We excluded the triallelic single nucleotide polymorphism in this analysis because of sample loss. Only 359 individuals entered the final model: $n=8$ missing MFQ-33 symptom scores at entry.
Increased liability for a subsequent episode of major depression was predicted by an interaction between the 5-HTTLPR ' $s$ ' allele and morning waking cortisol together with higher depressive symptoms in both genders (' $\mathrm{s}$ ' $\times$ morning cortisol, odds ratio $(\mathrm{OR})=10.2$ (s.e. $=10.6), z=2.23, P=0.026,95 \% \mathrm{CI}$ 1.3-78.4; higher depressive symptoms, $\mathrm{OR}=7.61 \quad$ (s.e. $=3.8$ ), $z=4.03, P<0.001,95 \%$ CI 2.8-20.4; gender, $\mathrm{OR}=1.83$ (s.e. $=0.78$ ), $z=1.46, P=0.14,95 \%$ CI $0.81-4.12$; 's' carriers alone, $\mathrm{OR}=0.05$ (s.e. $=0.06), \quad z=-2.37, P=0.018,95 \%$ CI 0.004-0.06; higher morning cortisol alone, $\mathrm{OR}=0.93$ (s.e. $=0.71$ ), $z=-0.09$, $P=0.93,95 \%$ CI 0.21-0.4.1, AIC $=191.4159)$. This fixed-effects regression model is based on 359 participants, as 8 individuals had missing self-report data at entry. There were $32 \quad(1 / 1=12$, $1 / s=13, s / s=7$ ) individuals who had subsequently become depressed. Addition of adversity number at entry (AIC= 192.6971), age at entry (AIC $=193.1101)$ or two-way interaction terms with gender (gender $\times$ cortisol; gender $\times$ depressive symptoms, AIC $=192.9879$ ) indicated a worse model and these terms were dropped.

The probability of being depressed at varying levels of morning cortisol is shown by genotype in Fig. 2.

Overall the findings suggest that the 5-HTTLPR genotype may moderate the association between morning waking cortisol and the subsequent onset of major depression for both males and females. The marginal predicted probability of being depressed for those with one or both copies of the short 's' allele begin to increase from the fiftieth centile (log level $\geqslant 1.03 \mathrm{ng} / \mathrm{ml}$ ) of morning cortisol upwards. Above this level are $21(68 \%)$ of the 32 individuals with depression and $17(81 \%)$ of these carry one or both 's' alleles.

\section{Discussion}

This study was limited to adolescent participants at increased psychosocial risk for depression, so as to yield a workable number of cases within the comparatively short follow-up period. Our findings may or may not apply in their entirety to a more general, community-based sample. However, the distribution of the 5-HTTLPR polymorphism in our sample resembled that reported by others in quite different sets of participants. ${ }^{1}$ In addition, the salivary levels of cortisol $^{13}$ are consistent with prior reports on adolescent populations.

\section{Salivary cortisol and 5-HTTLPR}

Our results confirm both between- and within-participant variation in longitudinal cortisol measures for both genders, here manifest as declining levels over consecutive school days. As argued by Hruschka and colleagues ${ }^{30}$ the use of mixed-effects modelling provides greater predictive accuracy of between-participant differences in hypothalamic-pituitary-adrenal activity and considerably improves the confidence in interpreting the association with individual-level outcomes such as clinical depression. Our findings in this paper are limited to waking morning cortisol, and may or may not apply to other measures of hypothalamicpituitary-adrenal activity, such as different time-point estimates, change across expected diurnal rhythm, longitudinal stability over time or responsiveness to a stimulus.

We show that salivary morning cortisol levels vary by 5-HTTLPR genotype together with sample day and gender. This finding is broadly consistent with that reported on a group of non-depressed older adults ${ }^{31}$ and recent experimental data on cortisol reactivity in adults at familial risk for depression or suffering from this disorder. ${ }^{11,12}$ We show that both $1 / \mathrm{s}$ and $\mathrm{s} / \mathrm{s}$ carriers have higher morning waking cortisol levels compared with 


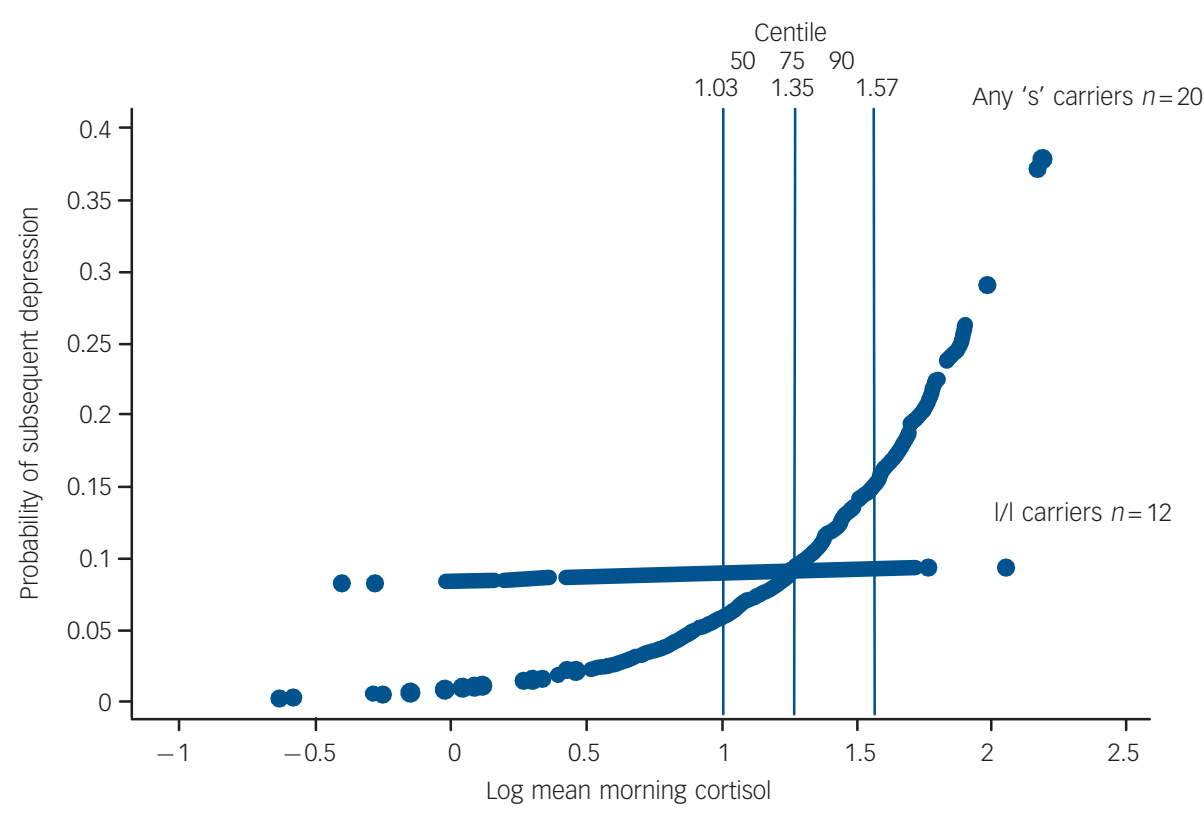

Fig. 2 Probability of subsequent depression episode onset by morning cortisol and 5-HTTLPR genotype.

those homozygous for the ' $\mathrm{l}$ ' allele for both genders. Further exploration of gende $\times$ gene effects on hypothalamic-pituitaryadrenal axis activity is warranted; for example genes associated with different monoaminergic systems may operate together to regulate individual cortisol responses to stress. $^{12}$ To our knowledge this is the first community-based prospective investigation to show that the short ' $\mathrm{s}$ ' allele is associated with individual differences in cortisol.

Individuals heterozygous or homozygous for the ' $s$ ' allele are less effective in their reuptake of serotonin because of lower transcriptional efficiency of 5 -HTTLPR. ${ }^{32}$ Serotonin has significant functions during development, early postnatal life and into adulthood and altered hypothalamic-pituitary-adrenal activity could derive from any or all of these periods. Experimental evidence in primates shows that the 's' allele is associated with increased glucocorticoid responses to disruption of parenting and social isolation and increasing likelihood of fearfulness and low social dominance. ${ }^{33,34}$ Studies on variations in maternal care in rodents have shown that epigenetic modification of the glucocorticoid receptor arises as a function of the quality of maternal behaviour, ${ }^{35}$ although whether this is also moderated by 5 -HTTLPR polymorphisms is unknown. The potential effects that individual differences in adverse childhood experiences may have on the association between 5-HTTLPR and morning cortisol levels remains a key topic for subsequent research. In addition serotonin is implicated in the process of neurogenesis in the hippocampus. Thus there may be direct effects on this structure which, in turn, alters the hypothalamic-pituitary-adrenal axis. ${ }^{36}$ There is also the observation that prolonged increases in cortisol may 'endanger' the brain to subsequent damaging events. ${ }^{37}$ Individuals with one or both copies of the 's' gene may be more vulnerable to such endangerment.

\section{Predicting depressive episode onset}

Our analysis suggests that for both genders the predictive risk of morning waking salivary cortisol for the subsequent onset of major depression is moderated by the presence of an ' $s$ ' allele of 5-HTTLPR. This both confirms and extends our prior prospective observations in adolescents and adult females, ${ }^{13-15}$ in which we showed that relatively higher morning cortisol is predictive of increased onsets of clinical depression. In the current sample of adolescents the contribution of non-clinical depressive symptoms at entry to the subsequent onset of disorder appears to be independent of the effects exerted by the interaction between 5-HTTLPR and higher morning cortisol. Interestingly female gender does not contribute to this prediction; this may be related to the observation that among the ' $\mathrm{s}$ ' carriers who become depressed there are 8 males and 12 females whereas among the 1/1 carriers who become depressed there are only 3 males but 9 females. Although small, this distribution of subsequent depression by genotype may suggest gender differences in the way that depressive disorders are moderated by 5-HTTLPR genotype. We suggest that this speculative observation deserves further investigation in a much larger community sample with similar genotyping data and hormonal assay measurement.

\section{Implications of an ' $s$ ' $\times$ cortisol interaction predicting depression}

Interpretation of the 5-HTTLPR $\times$ cortisol interaction in this high-risk sample is not straightforward and is limited by sample size. There is unequivocal confirmation of an association between the genotype and morning cortisol levels. We also confirm our previous prospective finding that higher levels of morning cortisol predict subsequent episodes of depression in this high-risk sample. In contrast, 5-HTTLPR itself does not predict depression (consistent with previous reports). ${ }^{1,3}$ Figure 2 shows that increased probability for clinical depression begins at cortisol levels within the range observed in $1 / 1$ participants. The specific effects of being an ' $s$ ' carrier on the probability of depression are restricted to levels of the log of morning waking cortisol greater than the fiftieth centile of this sample (i.e. above $1.03 \mathrm{ng} / \mathrm{ml}$ ). This suggests a corticoid-mediated association with subsequent depression that is associated with the ' $s$ ' allele for both genders. In this sample it may be that being at high psychosocial risk is a third 'factor', consistent with the gene $\times$ social environment findings. ${ }^{1-9} \mathrm{~A}$ three-way interaction between ' $\mathrm{s}$ ' allele $\times$ cortisol and some form of social adversity is plausible but not testable within the current sample, which is exclusively at high risk. Indeed 
within this adversity-enriched sample different levels of risk did not improve the prediction of depressive onsets nor influence the association between cortisol and genotype. Finally we cannot account for the potential influence that genetic and environmental factors may have had in evoking episodes of mental illness in childhood in this sample prior to ascertainment. It may be that prediction of depression provided by the 5 -HTTLPR $\times$ cortisol interaction is related to prior episodes or may only occur in those with recurrent episodes.

\section{Limitations}

The current findings must be interpreted in the light of a number of study limitations. First, the sample is one already 'at risk' for depression and the gene $\times$ hormone interaction requires replication in a much larger representative community sample. Second, the sample size and period of follow-up means that even with this design the proportion of depressive episodes is modest. Set against these limitations is evidence that the majority of depressive episodes arising in adolescents and young adults do so in those with prior childhood and adolescent adversities ${ }^{38}$ and also the fact that the current study is the only one so far reporting genetic and physiological data in a prospective design. Third, we lack longitudinal data on hypothalamic-pituitary-adrenal axis function. Almost all cortisol-behaviour studies, even prospective ones, have focused on one time series measure as a predictor or correlate of a behavioural measure or outcome.

\section{Further research}

The findings we report support the notion that there is an increase in hypothalamic-pituitary-adrenal axis activity in 's' carriers compared with those homozygous for the $1 / 1$ form of the 5-HTTLPR gene, and that this polymorphism moderates the association between higher cortisol and subsequent depression. This association might be a component of a biological pathway linking 5-HTTLPR with subsequent depression. We suggest that a plausible hypothesis for further investigation is that the short ' $s$ ' allele may act best as a true vulnerability factor in association with earlier adversities that result in atypical functional development of the hypothalamic-pituitary-adrenal axis resulting in higher tonic levels of morning cortisol.

Ian M. Goodyer, MD, FRCPsych, FmedSci, Alison Bacon PhD, Developmental Psychiatry Section, Department of Psychiatry, University of Cambridge, Cambridge; Maria Ban, PhD, Department of Clinical Neurosciences, University of Cambridge, Addenbrooke's Hospital, Cambridge; Tim Croudace, PhD, Developmental Psychiatry Section, Department of Psychiatry, University of Cambridge, Cambridge; Joe Herbert, PhD, Department of Physiology, Development and Neurosciences and the Cambridge Centre for Brain Repair, Cambridge Centre for Brain Repair, Cambridge, UK.

Correspondence: Ian M. Goodyer, Developmental Psychiatry Section, Department of Psychiatry, University of Cambridge, Douglas House, 18b Trumpington Road, Cambridge CB2 8AH, UK. Email: ig104@cam.ac.uk

First received 12 May 2008, final revision 3 Nov 2008, accepted 9 Dec 2008

\section{Funding}

This work was funded by a Wellcome Trust programme grant awarded to I.M.G. and J.H. T.J.C. is supported by a Career Scientist Award from the Department of Health.

\section{Acknowledgements}

We thank Helen Shires, Sarah Cleary and Jayne Wright for assays and DNA extraction Genotyping was conducted in the Clinical Neurosciences Laboratory (M.B.).

\section{References}

1 Caspi A, Sugden K, Moffitt TE, Taylor A, Craig IW, Harrington $H$, et al. Influence of life stress on depression: moderation by a polymorphism in the 5-HTT gene. Science 2003; 301: 386-9.

2 Cervilla JA, Molina E, Rivera M, Torres-Gonzalez F, Bellon JA, Moreno B, et al. The risk for depression conferred by stressful life events is modified by variation at the serotonin transporter 5HTTLPR genotype: evidence from the Spanish PREDICT-Gene cohort. Mol Psychiatry 2007; 12: 748-55.

3 Eley TC, Sugden K, Corsico A, Gregory AM, Sham P, McGuffin P, et al. Gene-environment interaction analysis of serotonin system markers with adolescent depression. Mol Psychiatry 2004: 9: 908-15.

4 Kaufman J, Yang BZ, Douglas-Palumberi H, Houshyar S, Lipschitz D, Krystal JH, et al. Social supports and serotonin transporter gene moderate depression in maltreated children. Proc Natl Acad Sci U S A 2004; 101: 17316-21.

5 Wilhelm K, Mitchell PB, Niven H, Finch A, Wedgwood L, Scimone A, et al. Life events, first depression onset and the serotonin transporter gene. Br J Psychiatry 2006; 188: 210-5.

6 Surtees PG, Wainwright NW, Willis-Owen SA, Luben R, Day NE, Flint J. Social adversity, the serotonin transporter (5-HTTLPR) polymorphism and major depressive disorder. Biol Psychiatry 2006; 59: 224-9.

7 Gillespie NA, Whitfield JB, Williams B, Heath AC, Martin NG. The relationship between stressful life events, the serotonin transporter (5-HTTLPR) genotype and major depression. Psychol Medicine 2005; 35: 101-11.

8 Uher R, McGuffin P. The moderation by the serotonin transporter gene of environmental adversity in the aetiology of mental illness: review and methodological analysis. Mol Psychiatry 2008; 13: 131-46.

9 Munafo MR, Durrant C, Lewis G, Flint J. Gene x environment interactions at the serotonin transporter locus. Biol Psychiatry 2009; 65: 211-9.

10 Jacobs N, Kenis G, Peeters F, Derom C, Vlietinck R, van Os J. Stress-related negative affectivity and genetically altered serotonin transporter function: evidence of synergism in shaping risk of depression. Arch Gen Psychiatry 2006; 63: 989-96.

11 Gotlib IH, Joormann J, Minor KL, Hallmayer J. HPA axis reactivity: a mechanism underlying the associations among 5-HTTLPR, stress, and depression. Biol Psychiatry 2008; 63: 847-951.

12 Jabbi, M, Korf J, Kema, IP, Hartman C, van der Pompe G, Minderaa RB, et al. Convergent genetic modulation of the endocrine stress response involves polymorphic variations of 5-HTT, COMT and MAOA. Mol Psychiatry 2007; 12: 483-90.

13 Goodyer IM, Herbert J, Tamplin A, Altham PME. Recent life events, cortisol, dehydroepiandrosterone and the onset of major depression in high-risk adolescents. Br J Psychiatry 2000; 177: 499-504.

14 Harris TO, Borsanyi S, Messari S, Stanford K, Cleary SE, Shiers HM, et al. Morning cortisol as a risk factor for subsequent major depressive disorder in adult women. Br J Psychiatry 2000; 177: 505-10.

15 Halligan SL, Herbert J, Goodyer IM, Murray L. Disturbances in morning cortisol secretion in association with maternal postnatal depression predict subsequent depressive symptomatology in adolescents. Biol Psychiatry 2007; 62: $40-6$.

16 Mannie ZN, Harmer CJ, Cowen PJ. Increased waking salivary cortisol levels in young people at familial risk of depression. Am J Psychiatry 2007; 164: 617-21.

17 Halligan SL, Herbert J, Goodyer IM, Murray L. Exposure to postnatal depression predicts elevated cortisol in adolescent offspring. Biol Psychiatry 2004; 55: 376-81.

18 Andrews MH, Matthews SG. Programming of the hypothalamo-pituitaryadrenal axis: serotonergic involvement. Stress 2004; 7: 15-27.

19 Bhagwagar Z, Hafizi S, Cowen PJ. Cortisol modulation of 5-HT-mediated growth hormone release in recovered depressed patients. J Affect Disord 2002; 72: 249-55.

20 Kaufman J, Birmaher B, Brent D, Rao U, Flynn C, Moreci P, et al. Schedule for Affective Disorders and Schizophrenia for School-Age Children-Present and Lifetime Version (K-SADS-PL): initial reliability and validity data. J Am Acad Child Adolesc Psychiatry 1997; 36: 980-8

21 American Psychiatric Association. Diagnostic and Statistical Manual of Mental Disorder (4th edn) (DSM-IV). APA, 1994.

22 Shaffer D, Gould MS, Brasio J, Ambrosini P, Fisher P, Bird H, et al. A Children's Global Assessment Scale (CGAS). Arch Gen Psychiatry 1983; 40: 1228-31.

23 Kent L, Vostanis P, Feehan C. Detection of major and minor depression in children and adolescents: evaluation of the Mood and Feelings Questionnaire. J Child Psychol Psychiatry 1997; 38: 565-73.

24 Daviss WB, Birmaher B, Melhem NA, Axelson DA, Michaels SM, Brent DA. Criterion validity of the Mood and Feelings Questionnaire for depressive 
episodes in clinic and non-clinic subjects. J Child Psychol Psychiatry 2006; 47: 927-34.

25 Goodyer IM, Herbert J, Altham PME, Pearson J, Secher S, Shiers S. Adrenal secretion during major depression in 8 to 16 year olds. I: Altered diurnal rhythms in salivary cortisol and dehydroepiandrosterone (DHEA) at presentation. Psychol Medicine 1996; 26: 245-56.

26 Guazzo EP, Kirkpatrick PJ, Goodyer IM, Shiers S, Herbert, J. Cortisol, dehydroepandrosterone (DHEA), and DHEA sulfate in the cerebrospinal fluid of man: relation to blood levels and the effects of age. J Clin Endocrinol Metab1996: 81: 3951-60.

27 Stata. STATA 10.0. 800-STATA-PC. Stata Corp, USA, 2006.

28 Netherton C, Goodyer IM, Tamplin A, Herbert J. Salivary cortisol and dehydroepiandrosterone in relation to puberty and gender. Psychoneuroendocrinology 2004; 29: 125-40.

29 Zalsman G, Huang YY, Oquendo MA, Burke AK, Hu XZ, Brent DA, et al. Association of a triallelic serotonin transporter gene promoter region (5-HTTLPR) polymorphism with stressful life events and severity of depression. Am J Psychiatry 2006; 163: 1588-93.

30 Hruschka DJ, Kohrt BA, Worthman CM. Estimating between- and withinindividual variation in cortisol levels using multilevel models.

Psychoneuroendocrinology 2005; 30: 698-714.

31 O'Hara R, Schroder C,M, Mahadevan R, Schatzberg AF, Lindley S, Fox S, et al. Serotonin transporter polymorphism, memory and hippocampal volume in the elderly: association and interaction with cortisol. Mol Psychiatry 2007; 12: $544-55$.
32 Lesch KP. Variation of serotonergic gene expression: neurodevelopment and the complexity of response to psychopharmacologic drugs. Eur Neuropsychopharmacol 2001; 11: 457-74.

33 Champoux M, Bennett A, Shannon C, Higley JD, Lesch KP, Suomi SJ. Serotonin transporter gene polymorphism, differential early rearing, and behavior in rhesus monkey neonates. Mol Psychiatry 2002; 7: 1058-63.

34 Jarrell H, Hoffman JB, Kaplan JR, Berga S, Kinkead B, Wilson ME. Polymorphisms in the serotonin reuptake transporter gene modify the consequences of social status on metabolic health in female rhesus monkeys. Physiol Behav 2008; 93: 807-19.

35 Weaver IC, Cervoni N, Champagne FA, D'Alessio AC, Sharma S, Seckl JR, et al. Epigenetic programming by maternal behavior. Nat Neurosci 2004; 7 847-54.

36 Bennett AJ, Lesch KP, Heils A, Long JC, Lorenz JG, Shoaf SE, et al. Early experience and serotonin transporter gene variation interact to influence primate CNS function. Mol Psychiatry 2002; 7: 118-22.

37 Herbert J, Goodyer IM, Grossman AB, Hastings MH, de Kloet ER, Lightman SL, et al. Do corticosteroids damage the brain? J Neuroendocrinol 2006; 18: 393-411.

38 Kim-Cohen J, Caspi A, Moffitt TE, Harrington H, Milne BJ, Poulton R. Prior juvenile diagnoses in adults with mental disorder: developmental follow-back of a prospective-longitudinal cohort. Arch Gen Psychiatry 2003; 60: 709-17.

\section{extra}

\section{Are you anti-psychiatry?}

\section{James Main}

One afternoon after passing finals, I was walking down the high street past the building in which we had taken our exams. I saw a placard positioned outside - 'alternative careers fair'. On impulse, I took a quick look around to ensure no one medically-inclined was in sight, and dipped inside.

In the limbo after 6 years of lectures, patients and essay crises, only houseman-hood loomed ahead. Perhaps this nudged me inside to glimpse what else might be out there! Of course, nothing that delivered the satisfaction of doctoring but bypassed weekend on-calls - TEFL or charity administration didn't appeal.

Then I found a rather different stall. The Citizens' Commission for Human Rights (CCHR) had a plush display with a laptop showing clips from a DVD. Curiosity drew me in. The laptop was screening a range of disturbing scenes, with a sinister accompanying soundtrack. The DVD cover pictured a roll of bank notes in a pool of blood. The title read: 'Psychiatry: An Industry of Death'. The hairs prickled on the back of my neck, but I was drawn to engage the middle-aged lady behind the table in conversation.

Our exchange covered some of the CCHR's concerns - 'child-drugging' (Ritalin for ADHD in America). I agreed there was probably some overzealous prescribing out there. ECT with no muscle relaxant - I explained to my new acquaintance (by now she knew I was a doctorto-be) that this was an historic practice and things are very different now in the UK though she didn't seem relieved by this.

Our unfolding discussion brought the strangest experience. The lady leaned over and asked with a warm smile and the expectant tone of making a like-minded ally, 'And are you anti-psychiatry?' I paused and considered my response. She was in high heels and I reckoned I could make the stairs a good deal faster than she, if things turned nasty.

'Umm - well - I don't think I can be anti-psychiatry, as I want to be a psychiatrist.' Her face fell. No like-minded friends were to be made that afternoon.

'Well,' she began, 'do you want to help people?' I hesitated - this sounded like the kind of trick question consultants ask you on ward rounds.

'Err - yes?'

'Well, that's a good start' she replied, clearly struggling with a polite young man who did not quite fit her box of 'human-rights-abusing-psychiatrist'.

Our parting was not disagreeable, but as I walked away, my heart was racing and I couldn't wait to get away. I had never felt so resented for occupying what seemed diplomatic middle ground. Only after I left did it occur to me that I had had to defend what I wanted to do with my life to a complete stranger with strong feelings against psychiatry.

The CCHR and its allied Church of Scientology as I later discovered are well known for their hostile attitude towards psychiatry, but my brief encounter highlighted for me the need to work reflectively and be able to justify our practice. I hope acquiring an understanding of other perspectives will go on helping me strengthen that middle ground where mutual understanding can alleviate sometimes irrational hostility and salvage therapeutic relationships. 